\title{
Studi Kelayakan Teknis Lokasi Perencanaan Trase Marisa-Tolinggula Provinsi Gorontalo
}

\author{
Lulu Rusliana Arva 1), Muhammad Yusuf Tuloli ${ }^{2)}$, Anton Kaharu ${ }^{3)}$ \\ 1),2),3) Jurusan Teknik Sipil, Fakultas Teknik, Universitas Negeri Gorontalo \\ e-mail : Iululaya185@gmail.com
}

\begin{abstract}
Abstrak
Penelitian ini berfokus pada aspek-aspek teknis lokasi yang dipetakan untuk memperoleh tingkat kelayakan lokasi perencanaan trase Marisa-Tolinggula. Tujuan penelitian untuk: 1) menyelidiki kondisi lokasi perencanaan trase Marisa-Tolinggula ditinjau dari aspek teknis lokasi yaitu penggunaan lahan, kemiringan lereng, jenis tanah, dan hidrologi; 2) menganalisa kondisi kelayakan lokasi terhadap pembangunan jalan baru rute Marisa- Tolinggula berdasarkan analisis kelayakan teknis lokasi; 3) memperoleh solusi dan rekomendasi untuk memperbaiki kelayakan lokasi perencanaan trase Marisa-Tolinggula. Lokasi penelitian meliputi beberapa kecamatan di Kabupaten Pohuwato dan Kecamatan Tolinggula. Analisis kuantitatif menggunakan peranti sistem informasi geofrafis ArcGIS yang kemudian diolah dengan metode skor. Pendekatan kualitatif selanjutnya dilakukan untuk mendeskripsikan hasil analisis. Hasil penelitian menunjukkan bahwa: 1) kondisi lahan di wilayah penelitian didominasi oleh tutupan lahan berupa hutan lahan kering sekunder $(43,23 \%)$, kemiringan lereng curam $(42,39 \%)$, jenis tanah podsolik merah kuning $(63,35 \%)$ dengan curah hujan yang sangat tinggi $(41,26 \%) ; 2)$ kondisi kelayakan lokasi terhadap pembangunan jalan Marisa- Tolinggula didominasi lahan dengan tingkat kelayakan kelas cukup (YC) sebesar $88,41 \%$; 3 ) solusi perbaikan lokasi perencanaan trase Marisa-Tolinggula berupa arahan rekomendasi jalan baru Marisa-Tolinggula, Trase Alternatif 2 dengan jarak tempuh sepanjang $58,84 \mathrm{~km}$.
\end{abstract}

Kata Kunci: Aspek Teknis, Kelayakan Lokasi, Trase Marisa-Tolinggula, Skor SIG

\begin{abstract}
This study focuses on the technical aspects of the mapped site to obtain the feasibility level of the Marisa-Tolinggula route planning site. The objectives of the research are to 1) investigate the condition of Marisa-Tolinggula trace planning location in terms of the technical aspects of the location of land use, slope, soil type, and hydrology; 2) to analyze site feasibility condition for the co nstruction of a new road of Marisa-Tolinggula route based on location technical feasibility analysis; 3) obtain solutions and recommendations to improve the feasibility of the MarisaTolinggula route planning site. The research sites include several sub-districts in Pohuwato and Tolinggula Sub-districts. Quantitative analysis uses ArcGIS geofrafis information system tools which are processed by the scoring method. Further qualitative approach were conducted to describe the results of the analysis. The results showed that: 1) the condition of land in the research area was dominated by land cover in the form of secondary dryland forest $(43,23 \%)$, steep slope $(42,39 \%)$, yellow podsolic soil type $(63,35 \%)$ with very high rainfall $(41,26 \%)$; 2) location feasibility condition on Marisa-Tolinggula road development is dominated by land with sufficient grade feasibility level (YC) equal to $88,41 \%$; 3) Marisa-Tolinggula route planning improvement solution in the form of rnew recommendation from Marisa- Tolinggula, Alternative Trase 2 with mileage 58,84 km.
\end{abstract}

Keywords: Technical GIS Score Aspect, Location of Feasibility, Marisa-Tolinggula Traffic,

\section{Pendahuluan}

Wilayah Paguyaman - Gorontalo - Kwandang sesuai arahan Rencana Tata

Ruang Wilayah Provinsi (RTRWP) Gorontalo akan dilakukan pembangunan jalan 
baru rute Marisa-Tolinggula. Sasaran pembangunan jaringan jalan tersebut yakni untuk mengurangi travel cost dan travel time perjalanan barang dan jasa yang melewati pusat Kota Gorontalo dan arus pergerakan lalu lintas disekitarnya. Selain itu, pembangunan prasarana transportasi darat diperlukan sebagai penghubung wilayah yang dapat membuka daerah-daerah terisolir serta mendorong kegiatan perekonomian pada daerah-daerah berpendapatan rendah disekitar wilayah pembangunan.Akan tetapi, wilayah Marisa-Tolinggula belum memiliki data fisik wilayah terutama menyangkut topografi, jenis tanah, maupun hidrologi yang diperlukan untuk mengetahui kelayakan lokasi pembangunan jaringan jalan.

\section{Metode}

Wilayah PenelitianLokasi-lokasi yang terdapat dalam garis imaginer sebagai wilayah penelitian tersebar pada 2 Kabupaten terdiri dari Kabupaten Pohuwato, dan Kabupaten Gorontalo Utara. Trase jalan yang direncanakan akan melalui 2 Kabupaten tersebut, yang meliputi 8 Kecamatan yaitu; Kec. Paguat Kec. Dengilo Kec. Marisa Kec. Buntulia Kec. Duhiadaa Kec. Patilanggio Kec. Randangan Kec. Taluditi Kec. Tolinggula.

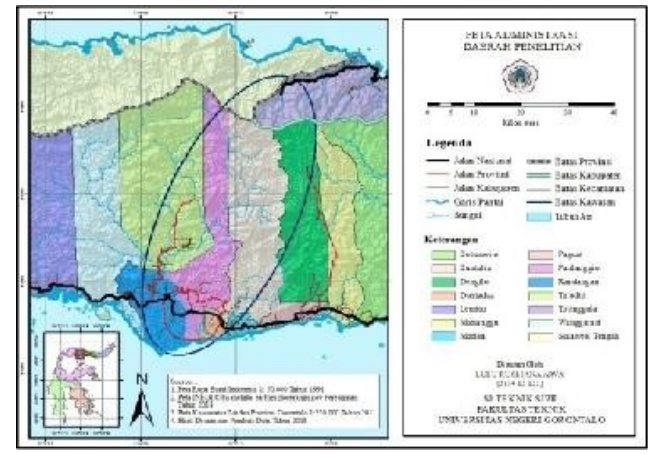

Gambar 1. Lokasi Wilayah Penelitian

\section{Alat dan Bahan}

Alat tulis menulis, Kamera digital, PC- Laptop yang dilengkapi software pendukung seperti ArcGIS 10.3, Peta Dasar Rupa Bumi Indonesia (RBI) wilayah penelitian, Peta topografi berupa peta penggunaan lahan (visualisasi Citra Quickbird 2018) kemiringan lereng dan peta jenis tanah (hasil proyeksi dari peta dasar RBI), serta peta hidrologi (RTRWP yang telah dikomplikasikan pada Badan Meteorologi dan Geofisika Provinsi Gorontalo, Tahun 2010) 


\section{Tahapan Penelitian}

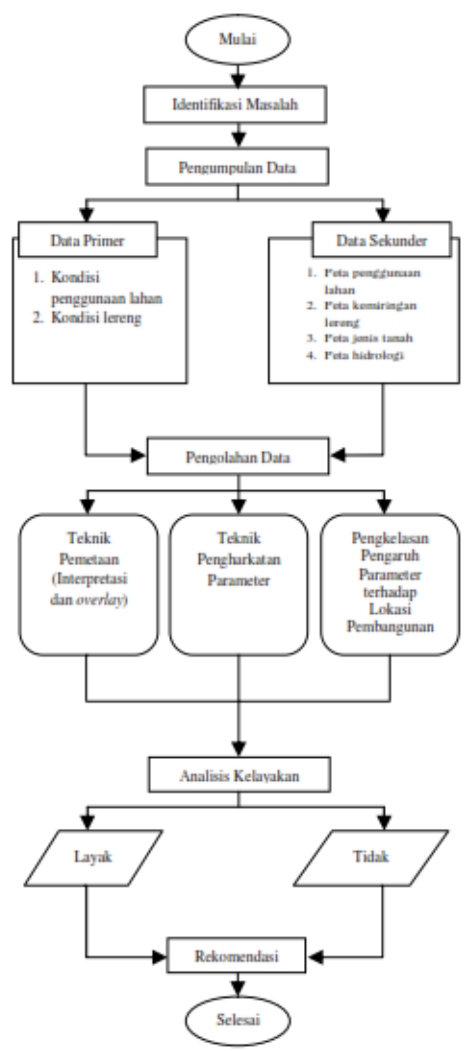

Gambar 2. Bagan Alir

\section{Tahap 1. Mengidentifikasi dan pengharkatan aspek teknis lokasi}

Pengolahan data diawali dengan melakukan kajian teoritik mengenai karakteristikvariabel yang mempengaruhi tingkat kelayakan suatu lokasi perencanaan trase. Pengolahan data dengan teknik pemetaan yang dilakukan menggunakan metode tumpangsusun (overlay) peta. Selanjutnya dilakukan teknik pengharkatan untuk menganalisis parameter-parameter.

Tabel 1. Harkat Penggunaan Lahan

\begin{tabular}{clc|c}
\hline Kelas & Jenis Penggunaan Lahan & Simbol & Skor \\
\hline I & Lahan terbuka atau lahan kosong & $\mathrm{T}$ & 5 \\
& Pertanian lahan kering & $\mathrm{Pc}$ & \\
& Perkebunan & $\mathrm{Pk}$ & \\
II & Hutan lahan kering & $\mathrm{Hp} / \mathrm{Hs}$ & 4 \\
& Semak belukar & $\mathrm{B}$ & \\
III & Lahan terbangun (perdagangan) & $\mathrm{D}$ & 3 \\
IV & Permukiman & $\mathrm{P}$ & 2 \\
V & Perairan & $\mathrm{A}$ & \\
\hline
\end{tabular}

(Sumber : SNI 7645:2010 skala 1:1.000.000) 
Tabel 2. Harkat Kemiringan Lereng

\begin{tabular}{cl|c|c|c}
\hline Kelas & Jenis Medan & Klasifikasi Medan & Simbol & Skor \\
\hline I & Datar & $0-8 \%$ & L1 & 5 \\
II & Berombak & $8-15 \%$ & L2 & 4 \\
III & Berbukit & $15-25 \%$ & L3 & 3 \\
IV & Curam & $25-45 \%$ & L4 & 2 \\
V & Sangat Curam & $>45 \%$ & L5 & 1 \\
\hline
\end{tabular}

(Sumber : PerMen PU No.20/PRT/M/2007)

Tabel 3. Harkat Kondisi Jenis Tanah

\begin{tabular}{clccc}
\hline Kelas & \multicolumn{1}{c}{ Jenis Tanah } & Deskripsi & Simbol & Skor \\
\hline I & $\begin{array}{l}\text { Regosol, Litosol, Organosol, } \\
\text { Renzina }\end{array}$ & Sangat Peka & T1 & 5 \\
II & $\begin{array}{l}\text { Andosol, Laterit, Grumosol, } \\
\text { Podsol, Podsolik }\end{array}$ & Peka & T2 & 4 \\
III & $\begin{array}{l}\text { Tanah hutan coklat, Coklat tak } \\
\text { bergamping, Mediteran } \\
\text { Latosol }\end{array}$ & Kurang Peka & T3 & 3 \\
IV & $\begin{array}{l}\text { Alluvial, Gley, Planosol, Hidromorf } \\
\text { kelabu biru, Laterit berair tanah }\end{array}$ & Tidak Peka & T4 & 2 \\
V & T5 & 1
\end{tabular}

(Sumber : SK Mentan No. 387/KPTSS / Um /11/1980 dan No. 638/KPt/UM /08/81

dalam Laya, 2013)

Tabel 4. Harkat Kondisi Hidrologi

\begin{tabular}{ccccc}
\hline Kelas & $\begin{array}{c}\text { Curah Hujan } \\
(\mathrm{mm} / \text { Tahun) }\end{array}$ & Deskripsi & Simbol & Skor \\
\hline I & $1000-1200$ & Sangat rendah & $\mathrm{H} 1$ & 5 \\
II & $1200-1400$ & Rendah & $\mathrm{H} 2$ & 4 \\
III & $1400-1600$ & Sedang & $\mathrm{H} 3$ & 3 \\
IV & $1600-1800$ & Tinggi & $\mathrm{H} 4$ & 2 \\
V & $1800-2000$ & Sangat tinggi & $\mathrm{H} 5$ & 1 \\
\hline \multicolumn{5}{c}{ (Sumber : Laya, 2013) }
\end{tabular}

Tahap 2. Proses overlay peta kelayakan teknis lokasi

Analisis dilakukan dengan teknik pengharkatan (Scoring) paremeter kelayakan untuk jalan rute Marisa- Tolinggula. Penentuan kelas kelayakan trase jalan dilakukan dengan menjumlahkan skor masing-masing parameter yang diteliti, kemudian dibagi dalam tiap kelas kelayakan.Kriteria kelayakan diperoleh berdasarkan nilai harkat menurut persamaan I = R/N (Sutrisno, 1981 dalam Laya, 2013). I = interval kelas, $\mathrm{R}=$ nilai tertinggi dikurangi nilai terendah, $\mathrm{N}=$ jumlah klasifikasi yang dikehendaki. Nilai akumulasi skor tertinggi untuk keempat parameter adalah 20 dan nilai 
akumulasi skor terendah untuk empat parameter adalah 4, jumlah klasifikasi yang dikehendaki adalah 5 . Sehingga interval tiap kelas yaitu:

$$
\begin{aligned}
& I=R / N \\
& I=(20-4) / 5 \\
& I=3.2 \text { (dibulatkan) } \\
& I=4
\end{aligned}
$$

Interval nilai kelayakan terbagi menjadi 5 kelas yaitu kelayakan tinggi (YT), kelayakan

\begin{tabular}{|c|c|c|c|}
\hline Kelas & Interval & Kriteria & Keterangan \\
\hline $\mathrm{YT}$ & $17-20$ & Tinggi & $\begin{array}{l}\text { Daya dukung lahan dan parameter lain dalam } \\
\text { kondisi sangat baik dan sangat layak untuk trase } \\
\text { jalan }\end{array}$ \\
\hline YS & $13-16$ & Sedang & $\begin{array}{l}\text { Daya dukung lahan dan parameter lain dalam } \\
\text { kondisi baik, perlu sedikit perbaikan dan layak } \\
\text { untuk trase jalan }\end{array}$ \\
\hline YC & $9-12$ & Cukup & $\begin{array}{l}\text { Daya dukung lahan dan parameter lain dalam } \\
\text { kondisi cukup, cukup banyak perbaikan dan cukup } \\
\text { layak untuk trase jalan }\end{array}$ \\
\hline TB & $5-8$ & Tidak Baik & $\begin{array}{l}\text { Daya dukung lahan dan parameter lain dalam } \\
\text { kondisi kurang baik, banyak perbaikan dan tidak } \\
\text { layak sementara untuk trase jalan }\end{array}$ \\
\hline TS & $1-4$ & $\begin{array}{c}\text { Tidak Sama } \\
\text { Sekali }\end{array}$ & $\begin{array}{l}\text { Daya dukung lahan dan parameter lain dalam } \\
\text { kondisi tidak baik, sangat banyak perbaikan dan } \\
\text { tidak layak selamanya untuk trase jalan }\end{array}$ \\
\hline
\end{tabular}
sedang (YS), kelayakan cukup (YC), tidak layak (TB) dan tidak layak sama sekali (TS).

Tabel 5. Klasifikasi Kelayakan Lokasi

(Sumber : Arva, 2018)

\section{Tahap 3. Analisis solusi peningkatan kelayakan teknis lokasi}

Rekomendasi solusi pada perbaikan kelayakan teknis adalah dengan perencanaan alternatif trase baru berdasar pada peta kelayakan lokasi. Alternatif trase direncanakan secara subjektif dan didistrubusikan ke wilayah-wilayah dengan tingkat kelayakan sedang (YS) sampai tingkat kelayakan cukup (YC). Skenario trase kemudian dianalisis melalui proses tumpangsusun (overlay) pada peta aspek teknis lokasi. Masing- masing skenario diproses pada peta penggunaan lahan, kemiringan lereng, jenis tanah dan curah hujan. Analisis dilakukan untuk memperoleh informasi panjang jalan skenario trase yang melalui berbagai kondisi. 


\section{Hasil dan Pembahasan}

\section{Identifikasi dan Pengharkatan Aspek}

\section{Teknis Lokasi}

Pengharkatan dan pemberian skor diterapkan pada aspek-aspek teknis yang berpengaruh pada tingkat kelayakan lokasi, berupa penggunaan lahan, kemiringan lereng, kondisi jenis tanah serta kondisi tebal curah hujan di wilayah penelitian. Parameter aspek teknis lokasi yang telah ditentukan nilai skor kemudian diproyeksi pada data-data peta, untuk selanjutnya dilakukan pengecekan lapangan melalui survai.

Pemetaan scoring keseluruhan parameter aspek teknis selanjutnya dilakukan proses overlay. Hasil analisis overlay peta-peta tersebut menghasilkan peta kelayakan lokasi perencanaan trase dengan beberapa tingkatan kelayakan. Trase jalan baru direncanakan melalui area-area dengan tingkat kelayakan cukup sampai sangat tinggi.

\section{Kondisi Penggunaan Lahan}

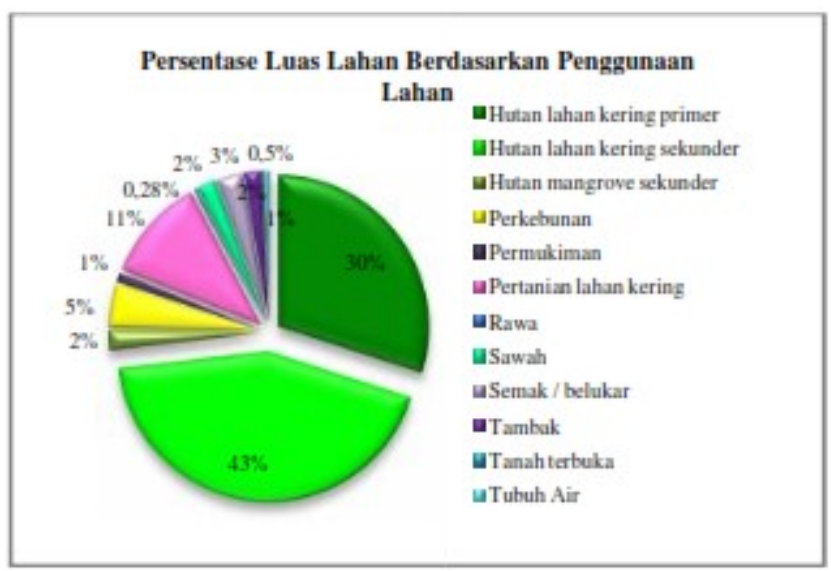

Gambar 3. Persentase Luas Penggunaan Lahan di Wilayah Penelitian

Hutan lahan kering sekunder dan hutan lahan kering primer mendominasi wilayah penelitian lebih dari $73 \%$ mengindikasikan wilayah ini berpotensi besar untuk pembukaan jalan baru Marisa-Tolinggula. Lahan perkebunan dan pertanian lahan kering sebesar $15 \%$ dari wilayah penelitian memungkinkan pembangunan jalan dengan adanya pergantian tata guna lahan yang dapat menimbulkan biaya tambahan (extra cost). Lahan permukiman meskipun hanya seluas 1\% dari wilayah penelitian, sebaiknya trase jalan yang akan dirancang tidak melewati area-area permukiman untuk menghindari adanya biaya pembebasan lahan. Trase jalan baru tidak pula melewati lahan rawa, sawah, tambak, dan hutan mangrove sekunder. Sebesar $7 \%$ luasan dari wilayah penelitian dapat berdampak pada kerugian biaya 
pelaksanaan. Hal ini disebabkan oleh pematangan lahan dan pengolahan tanah agar lahan siap untuk pembangunan jalan.

\section{Kondisi Kemiringan Lereng}

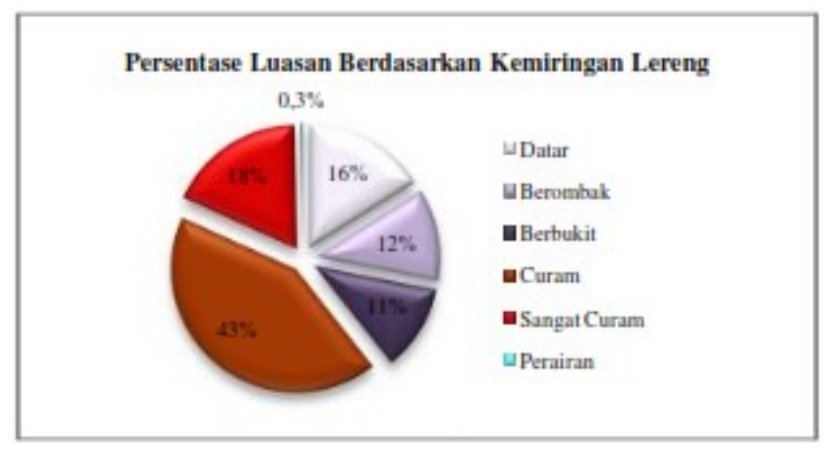

Gambar 4. Persentase Luas Lahan Berdasarkan Kemiringan Lereng

Kemiringan lereng sangat mempengaruhi pemilihan lokasi perencanaan trase, sehingga lahan dengan persen kemiringan lereng yang rendah atau termasuk lahan datar sangat sesuai untuk pembangunan jalan. Namun, besarnya luas lahan dengan kemiringan lereng $0-8 \%$ atau datar hanya sebesar $16.04 \%$ dari wilayah penelitian. Lokasi perencanaan trase Marisa-Tolinggula pun sebaiknya melalui lahan-lahan dengan kemiringan lereng $0-8 \%$ tersebut untuk meningkatkan kinerja dan kemudahan dalam pelaksanaan dan mengurangi biaya timbunan dan galian.

\section{Kondisi Jenis Tanah}

Parameter dalam menentukan jenis tanah umumnya berdasarkan sifat fisik dan kimia. Parameter ini sering digunakan untuk keperluan rekayasa teknis. Berdasarkan peta tanah dari peta dasar RBI oleh Bakosurtanal skala 1:25.000, di wilayah penelitian terdapat jenis tanah Podsolik, Mediteran, Latosol dan Alluvial.

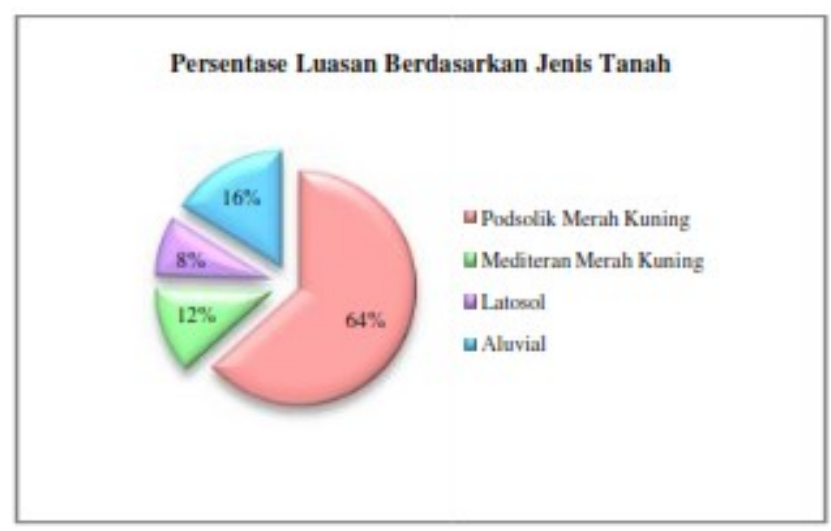

Gambar 5. Persentase Luas Lahan Berdasarkan Jenis Tanah

Kondisi Curah Hujan Intensitas curah hujan sangat mempengaruhi terjadinya erosi dan besar pengaruhnya pada stabilitas lereng. Air hujan sebagian dapat melimpas kebawah melalui lereng galian dan sebagian lainnya terinfiltrasi kedalam 
lereng. Lereng menjadi jenuh air, kondisi tanah yang peka terhadap erosi dapat menimbulkan kemungkinan terjadinya longsor.

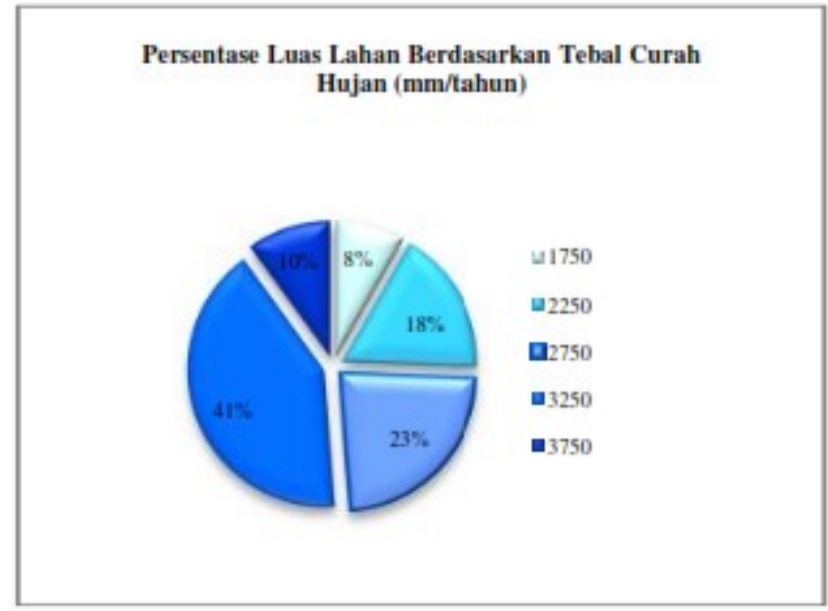

Gambar 6. Persentase Luas Lahan Berdasarkan Curah Hujan

Peningkatan Kelayakan LokasiKondisi penggunaan lahan lebih dahulu dioverlay terhadap skenario trase jalan. Dampak pembukaan jalan baru kiranya mempertimbangkan resiko kerusakan lingkungan dan ekosistem hutan. Resiko pembebasan lahan juga terjadi pada masing-masing skenario trase. Jalan yang melalui lahan perkebunan, permukiman, pertanian, sawah dapat menimbulkan biaya tambahan guna pembebasan lahan untuk pembukaan jalan baru.

Tabel 6. Tumpangsusun Panjang Trase dengan Kondisi Penggunaan Lahan (Km)

\begin{tabular}{cccc}
\hline Penggunaan Lahan & Alternatif 1 & Alternatif 2 & PU \\
\hline Hutan lahan kering primer & 15.09 & 20.03 & 29.29 \\
Hutan lahan kering sekunder & 22.63 & 30.31 & 25.78 \\
Perkebunan & 6.67 & & \\
Permukiman & 3.42 & 0.96 & 1.12 \\
Pertanian lahan kering & 5.39 & 2.69 & 3.91 \\
Sawah & 2.49 & & 0.37 \\
Semak / belukar & 3.61 & 4.84 & 1.55 \\
Tubuh Air & 0.38 & 0.14 & 1.61 \\
\hline Panjang Total (Km) & 59.69 & 58.98 & 63.63 \\
\hline (Sumber : Hasil pengolahan data, 2018)
\end{tabular}




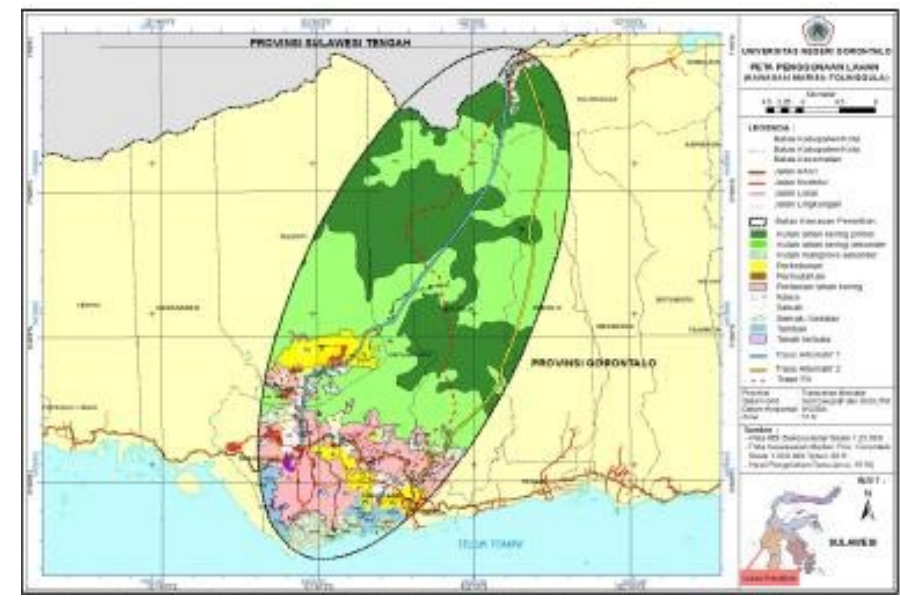

Gambar 7. Tumpangsusun Trase PU dan Trase Alternatif Terhadap Peta Penggunaan Lahan Wilayah Penelitian

Kondisi kemiringan lereng yang dilalui masing-masing skenario trase dapat diketahui pula melalui analisis overlay. Tindakan teknis selanjutnya perlu direncanakan seperti rekayasa geometrik jalan pada proses galian dan timbunan. Pembangunan dinding penahan tanah sebagai upaya peningkatan stabilitas lereng juga perlu dibangun pada lokasi- lokasi lereng sangat curam. Tindakan alternatif lain yang dapat dilakukan adalah dengan membangun terowongan yang memotong kontur-kontur tinggi, namun hal ini memerlukan perencanaan lebih lanjut.

Tabel 7. Tumpangsusun Panjang Trase dengan Kondisi Lereng (Km)

\begin{tabular}{cccc}
\hline Kemiringan Lereng & Alternatif 1 & Alternatif 2 & PU \\
\hline $0-8 \%$ & 2.66 & 2.95 & 4.78 \\
$8-15 \%$ & 0.03 & 5.18 & 3.73 \\
$15-25 \%$ & 8.31 & 9.64 & 9.07 \\
$25-45 \%$ & 48.70 & 41.21 & 46.06 \\
$>45 \%$ & 11.67 & 6.01 & 15.00 \\
Tubuh Air & 0.38 & & 1.60 \\
Panjang Total (Km) & 59.69 & 58.98 & 63.63 \\
\hline
\end{tabular}

(Sumber : Hasil pengolahan data, 2018) 


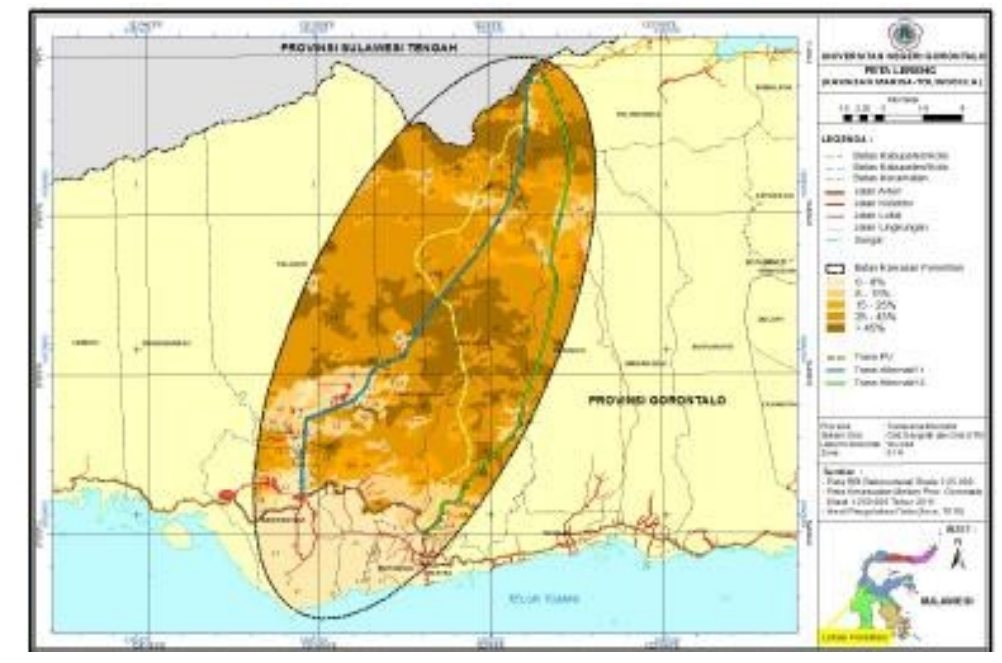

Gambar 8. Tumpangsusun Trase PU dan Trase Alternatif Terhadap Peta Kemiringan

\section{Lereng Wilayah Penelitian}

Aspek teknis selanjutnya yang dioverlay dengan skenario trase adalah jenis tanah dan curah hujan. Kondisi masing-masing skenario yang melalui lokasi dengan tebal curah hujan yang sangat tinggi memerlukan perencanaan drainase yang baik untuk meminimalisir kerusakan konstruksi jalan akibat genangan air. Disamping itu, jenis tanah dengan sifat permebalitas rendah seperti tanah alluvial perlu ditangani. Tindakan yang dapat dilakukan seperti peningkatan daya dukung tanah.

Tabel 8. Tumpangsusun Panjang Trase dengan Kondisi Tanah (Km)

\begin{tabular}{cccc}
\hline Kriteria & Alternatif 1 & Alternatif 2 & PU \\
\hline Aluvial & 2.66 & 2.95 & 4.78 \\
Latosol & 0.03 & 5.18 & 3.73 \\
Mediteran Merah & 8.31 & 9.64 & 9.07 \\
$\begin{array}{c}\text { Kuning } \\
\text { Podsolik Merah }\end{array}$ & 48.70 & 41.21 & 46.06 \\
$\quad$ Kuning & 59.69 & 58.98 & 63.63 \\
\hline Panjang Total $(\mathrm{Km})$ &
\end{tabular}

(Sumber : Hasil pengolahan data, 2018)

Tabel 9. Tumpangsusun Panjang Trase dengan Curah Hujan (Km)

\begin{tabular}{cccc}
\hline Kriteria & Alternatif 1 & Alternatif 2 & PU \\
\hline Tinggi & & 4.91 & 8.03 \\
Sangat Tinggi & 59.69 & 54.07 & 55.60 \\
Panjang Total $(\mathrm{Km})$ & 59.69 & 58.98 & 63.63 \\
\hline
\end{tabular}

(Sumber : Hasil pengolahan data, 2018) 


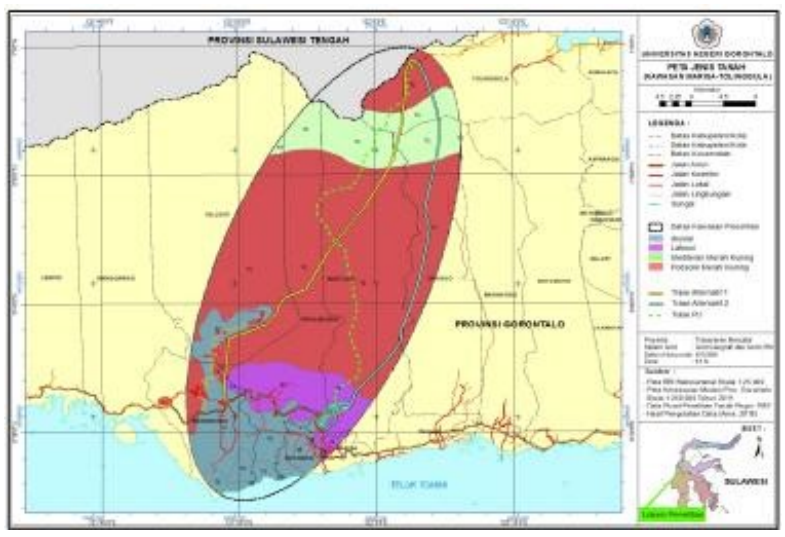

Gambar 9. Tumpangsusun Trase PU dan Trase Alternatif Terhadap Peta Jenis Tanah Wilayah Penelitian

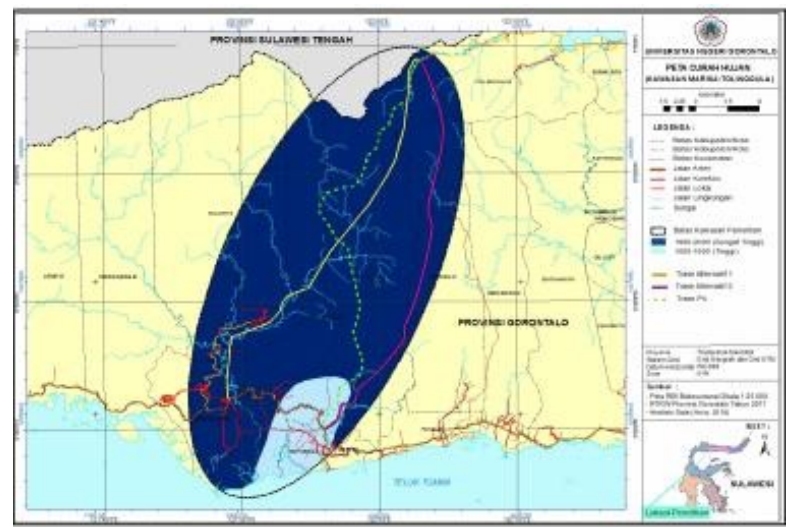

Gambar 10. Tumpangsusun Trase PU dan Trase Alternatif Terhadap Peta Jenis Tanah Wilayah Penelitian

Pemilihan Skenario TraseSkenario trase yang direncanakan berdasarkan hasil analisis penelitian dipilih berdasarkan pertimbangan aspek- aspek yang berkaitan dengan pembangunan jalan baru. Beberapa aspek yang menjadi kriteria adalah jarak tempuh, konektivitas titik awal, tata ruang kawasan permukiman dan tingkat kelayakan lokasi pembangunan. Perbandingan panjang jalan Trase Alternatif 1, Trase Alternatif 2 dan Trase PU memperlihatkan kondisi kelayakan lokasi sepanjang trase yang direncanakan dapat dilihat pada Tabel 10 dan Gambar 11.

Tabel 10. Panjang Trase Jalan dan Kriteria Kelayakan Lokasi (Km)

\begin{tabular}{cccc}
\hline Kriteria & Alternatif 1 & Alternatif 2 & PU \\
\hline Sedang & 20.74 & 11.37 & 2.98 \\
Cukup & 37.51 & 47.47 & 58.94 \\
Tidak Baik & 1.44 & - & 1.72 \\
Panjang Total & 59.69 & 58.84 & 63.63 \\
\hline
\end{tabular}

(Sumber : Hasil pengolahan data, 2018) 


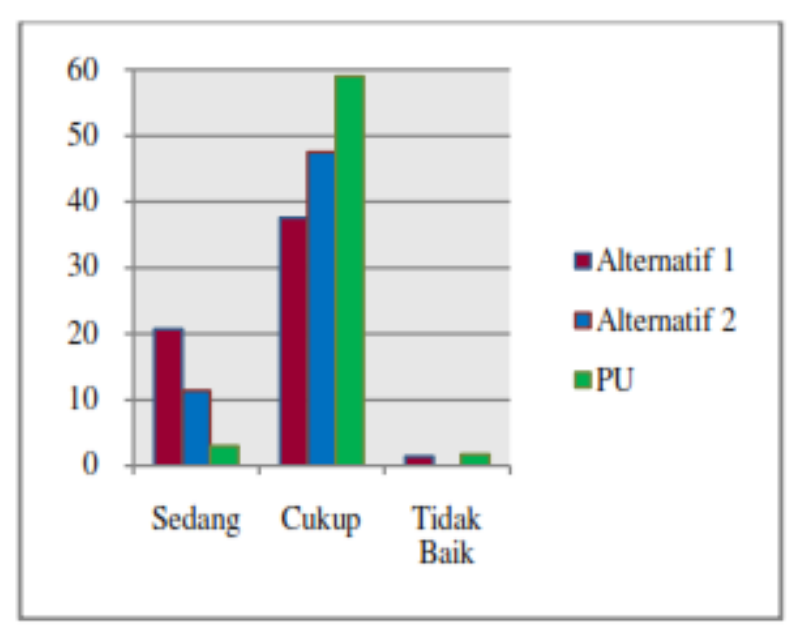

Gambar 11. Panjang Trase Terhadap Tingkat Kelayakan Lokasi (Km)

Skenario trase PU melalui lahan-lahan dengan kelas kelayakan cukup (YC) serta dibeberapa titik memotong aliran sungai. Skenario Alternatif 1 memiliki kondisi kelayakan lahan Kecamatan Randangan dan Kecamatan Taluditi yang sangat potensial untuk perencanaan jalan baru. Kondisi kelayakan lokasi sepanjang skenario Trase Alternatif 2 sama sekali tidak melalui lokasi kriteria tidak baik.

Gambar 12. Trase PU dan Trase Alternatif Terhadap Peta Tingkat Kelayakan Lokasi

Pemilihan skenario berdasarkan jarak tempuh mengakomodasi waktu tempuh perjalanan serta biaya operasional kendaraan pengguna jalan. Trase MarisaTolinggula oleh PU memiliki panjang total $\pm 63,629 \mathrm{~km}$. Adapun rekomendasi Trase Alternatif 1 dengan panjang jalan $\pm 59,691 \mathrm{~km}$ lebih pendek $4 \mathrm{~km}$ dari panjang trase yang dirilis oleh PU. Rekomendasi lainnya adalah Trase Alternatif 2 dengan panjang total $\pm 58,843 \mathrm{~km}$, secara subjektif sebagai jarak tempuh paling pendek diantara ketiga skenario trase. Aspek berikutnya sebagai bahan pertimbangan pemilihan skenario trase alternatif adalah rencana tata ruang kawasan pemukiman. Skenario Alternatif 1 melalui lahan permukiman sepanjang $3.4 \mathrm{~km}$, Alternatif 2 sepanjang 0,9 $\mathrm{km}$, dan skenario PU sepanjang $1.1 \mathrm{~km}$, yang menandakan adanya pembebasan lahan permukiman warga setempat. Pertimbangan selanjutnya berdasarkan konektivitas trase dinilai pada starting point (titik awal) masing-masing skenario. Trase Alternatif 1 direncanakan berada di Kecamatan Randangan yakni sejauh 20 km dari Kecamatan Marisa. Sehingga dapat menambah waktu perjalanan, jarak tempuh dan biaya operasional kendaraan bagi pengendara arah Marisa-Isimu-Kota Gorontalo. Disisi lain, titik awal trase skenario PU dan Alternatif 2 berlokasi di Kecamatan Marisa yang bertindak sebagai pusat perekonomian Kabupaten Pohuwato. Pemilihan skenario trase dilakukan dengan skoring, nilai skor tertinggi untuk aspek yang dinilai adalah 3 = Baik, 2 = Cukup Baik, 1 = Kurang Baik. 
Tabel 11. Skor Aspek Pertimbangan Pemilihan Skenario Trase

\begin{tabular}{cccccc}
\hline Skenario & $\begin{array}{c}\text { Jarak } \\
\text { Tempuh }\end{array}$ & $\begin{array}{c}\text { Kelayakan } \\
\text { Lokasi }\end{array}$ & $\begin{array}{c}\text { Tata Ruang } \\
\text { Kawasan } \\
\text { Pemukiman }\end{array}$ & $\begin{array}{c}\text { Konektifitas } \\
\text { (Titik Awal) }\end{array}$ & $\begin{array}{c}\text { Jumlah } \\
\text { Skor }\end{array}$ \\
\hline Alternatif 1 & 2 & 3 & 1 & 1 & 7 \\
Alternatif 2 & 2 & 2 & 3 & 3 & 10 \\
PU & 2 & 1 & 3 & 3 & 9 \\
\hline
\end{tabular}

(Sumber : Hasil pengolahan data, 2018)

Hasil penilaian aspek pertimbangan pemilihan skenario trase baru adalah Trase Alternatif 2 jarak tempuh $58,843 \mathrm{~km}$, tidak melalui lokasi pembangunan tingkat kelayakan tidak baik, titik awal berada di pusat perekonomian Kabupaten Pohuwato. Trase diharapkan mampu meningkatkan aksesibilitas dan distribusi komoditas unggulan pada kawasan Marisa-Tolinggula

\section{Kesimpulan}

Kondisi lahan di wilayah penelitian didominasi oleh tutupan lahan berupa hutan lahan kering sekunder (43,226\%), kemiringan lereng curam $(42,386 \%)$, jenis tanah podsolik merah kuning $(63,350 \%)$ dengan curah hujan yang sangat tinggi $(41,261 \%)$. Kondisi kelayakan lokasi terhadap pembangunan jalan baru MarisaTolinggula didominasi lahan dengan tingkat kelayakan kelas cukup (YC) sebesar $88,412 \%$. Solusi perbaikan lokasi perencanaan trase Marisa-Tolinggula dengan arahan rekomendasi jalan baru Marisa- Tolinggula, Trase Alternatif 2 dengan jarak tempuh $58,843 \mathrm{~km}$.

\section{Daftar Pustaka}

Alfianto, F. (2017). Analisa Kesesuaian Lahan Untuk Lokasi Pengembangan Permukiman Menggunakan Metode Scoring (Studi Kasus: Surabaya Timur). Skripsi. Progam Sarjana Institut Teknologi Sepuluh November.

BAKOSURTANAL. (2016). Peran Informasi Geospasial Dalam Pembangunan Indonesia. Bogor:

Badan Informasi Geospasial dan Masyarakat Penulis IImu Pengetahuan dan Teknologi (MAPIPTEK).Dep.PU. (2005).

Pedoman Konstruksi dan Bangunan tentang Studi Kelayakan Proyek Jalan dan Jembatan Pd T-19- 2005-B. Bandung.Politeknik Negeri Bandung. Bandung.

Kaharu, A. (2014). Pengembangan Jaringan Jalan Berdasarkan Daya Dukung Wilayah di Provinsi Gorontalo. Disertasi. Program Pascasarjana Universitas Gadjah Mada. Yogyakarta.

Laya, A. (2013). Kajian Hidrogeomorfologi Banjir Di Kota Gorontalo. Disertasi. Program Pascasarjana Universitas Gadjah Mada. 
Wibawa, R. F. (2016). Analisis Spasial Penentuan Lokasi Jalan di Daerah Istimewa Yogyakarta Menggunakan Teknologi Penginderaan Jauh dan Sistem Informasi Geografis. Skripsi. Program Sarjana Universitas Muhammadiyah. Surakarta. 